\title{
ANTEPROJETO DE UMA UNIDADE DA SAÚDE FAMILIAR - USF ADAPTADA AO CLIMA QUENTE E SECO NO MUNICÍPIO DE CAJAZEIRAS-PB
}

\author{
PROJECT FOR A FAMILY HEALTH UNIT - USF ADAPTED TO THE \\ HOT AND DRY CLIMATE IN THE CITY OF CAJAZEIRAS-PB
}

\author{
Arthur Bruno Vieira Batista ${ }^{1}$ \\ Mirela Davi de Melo $^{2}$ \\ Rafael Costa de Carvalho Abrantes ${ }^{3}$ \\ Isabel Sobral de Abreu e Lima ${ }^{4}$ \\ André Ferreira Costa ${ }^{5}$ \\ Pollyanna Priscila de Souza Lima
}

\footnotetext{
${ }_{1}^{1}$ Graduando em Arquitetura e Urbanismo pela Faculdade Santa Maria - FSM.

${ }^{2}$ Possui graduação em Arquitetura e Urbanismo pela Universidade Federal da Paraíba (UFPB 2016), especialização em Gestão de Políticas do Patrimônio Cultural pela Faculdade Maurício de Nassau (2018) e mestrado em Desenvolvimento Urbano (MDU) pelo Departamento de Arquitetura e Urbanismo da Universidade Federal de Pernambuco (UFPE - 2019), canalizando seus estudos para o projeto paisagístico e o bem-estar. Exerce o cargo de arquiteto como técnica na Prefeitura Municipal de Marí/ PB desde 2016, atuando na elaboração de projetos arquitetônicos e urbanos. É docente na Faculdade Santa Maria (FSM) desde 2018.

${ }^{3}$ Possui graduação em Arquitetura e Urbanismo pela Universidade Federal da Paraíba (2014) e mestrado em Energias Renováveis pela Universidade Federal da Paraíba (2017) na linha de pesquisa em Meio Ambiente, Economia e Aproveitamento Energético. Atualmente é professor da Faculdade Santa Maria (FSM) em Cajazeiras e das Faculdades Integradas de Patos (FIP). Tem experiência na área de Arquitetura e Urbanismo e Sustentabilidade, com ênfase em Projeto de Arquitetura e Urbanismo.

${ }^{4}$ Arquiteta e Urbanista graduada pelo Centro universitário Maurício de Nassau de Recife em 2017 e Pós Graduada em Acústica Arquitetônica e lluminação pela Faculdade de Ciências Humanas ESUDA em 2018. Pós Graduanda em Docência em Ensino Superior pela Faculdade Santa Maria de Cajazeiras (FSM). Docente da Faculdade Santa Maria (FSM), tem experiência na área de Arquitetura e Urbanismo, com ênfase em Planejamento e Projetos de Acústica Arquitetônica, atuando principalmente com projetos, obras e consultoria.

${ }^{5}$ Desde 2016 é professor da Faculdade Santa Maria de Cajazeiras, atuando no curso de Arquitetura e Urbanismo e no curso de Engenharia Civil. Possui graduação em Engenharia Civil pela Universidade Federal da Paraíba (2014), graduação em Construção de Edifícios pelo Instituto Federal de Educação, Ciência e Tecnologia da Paraíba (2014) e especialização em Gerenciamento de Projetos pela Fundação Getúlio Vargas (2016). Tem experiência profissional na área de Engenharia Civil, com ênfase em Gerenciamento e Execução de Obras.

${ }^{6}$ Arquiteta e Urbanista graduada pelo Centro Universitário de João Pessoa - UNIPÊ. Mestre em Qualidade do Ambiente Construído pelo Programa de Pós-Graduação em Arquitetura e Urbanismo PPGAU-UFPB. Atualmente é professora do curso de Arquitetura e Urbanismo da Faculdade Santa Maria e Faculdade Paraíso do Ceará- FAP atuando principalmente nos seguintes temas: bioclimatismo na arquitetura e urbanismo, Sustentabilidade, conforto ambiental das edificações, simulações computacionais, história da arquitetura moderna e contemporânea e Plataforma BIM.
} 
RESUMO: Este trabalho tem como objetivo elaborar um anteprojeto de uma Unidade de Saúde da Família (USF) adaptada ao clima quente e seco no Município de Cajazeiras - PB. Visto que expandir e qualificar a Atenção Básica (AB) é um dos objetivos do Ministério da Saúde (MS) atualmente, e que a Cidade de Cajazeiras, em seus últimos tempos, expandiu-se em grande escala, sendo que tais áreas carecem de equipamento público de saúde, obrigando a população do Loteamento das Palmeiras a se descolocar a outras unidades de demais bairros em busca de atendimento, que, por sua vez, são prestados com baixa qualidade dos ambientes. O intuito é apresentar uma edificação que contenha espaços qualificados e que possibilite o funcionamento das atividades previstas; aplicar técnicas e soluções projetuais mais adequadas ao clima quente e seco quanto ao conforto ambiental e a funcionalidade, além de conhecer e empregar os parâmetros e exigências da legislação vigente relacionado à prestação de serviço; gerar diagnóstico sobre a real situação de USF's existentes na localidade; e contribuir como referência para projetos dentro da ambiência hospitalar. Para atingir o objetivo proposto, os seguintes procedimentos metodológicos foram aplicados: pesquisa bibliográfica; análise de duas unidades de saúde existentes através de visitas técnicas para observações in loco, o levantamento fotográfico e planimétrico; análise de projetos correlatos utilizando o método Boker; diretrizes da proposta; elaboração do processo projetual e, ao final, a criação da proposta de anteprojeto de uma USF.

DESCRITORES: Arquitetura hospitalar. Sistema Único de Saúde. Unidade de Saúde da Família. Paraíba. Clima quente e seco.

ABSTRACT: The objective of this work was to prepare a draft of a Family Health Unit (FHU) adapted to the hot and dry climate in the Municipality of Cajazeiras - PB. Since expanding and qualifying Primary Care (PC) is one of the objectives of the Ministry of Health (MH), and that the City of Cajazeiras, in recent times, has expanded on a large scale, and such areas lack public health equipment, obliging the population of Loteamento das Palmeiras to dislocate to other units in other neighborhoods to seek care, which, in turn, is provided with poor quality of the environments. The intention is to present a building that contains qualified spaces, allowing for the operation of the planned activities; applying techniques and designing solutions more appropriate to the hot and dry climate regarding environmental comfort and functionality, in addition to knowing and using the parameters and requirements of current legislation related to the provision of service; generating diagnosis about the actual situation of FHUs existing in the locality; and contributing as a reference for projects within the hospital environment. To reach the proposed objective, the following methodological procedures were applied: bibliographic research; analysis of two existing health units through technical visits for on-site observations, photographic and planimetric surveys; analysis of related projects using the Boker method; proposal guidelines; elaboration of the design process and, at the end, the creation of the draft proposal of a FHU.

DESCRIPTORS: Hospital architecture. Unified Health System. Family Health Unit. Paraíba. Hot and dry weather. 


\section{INTRODUÇÃO}

Todo cidadão, desde seu nascimento até o dia de sua morte, tem como garantia 0 acesso a ambientes hospitalares para avaliações, diagnósticos e tratamento de doenças, disposto pelo Art. 196, na Constituição da República Federativa do Brasil de 1988, quando retrata que "A saúde é direito de todos e dever do Estado". Já conforme a Portaria n. 1.820, de 13 de agosto de 2009, que "Dispõe sobre os direitos e deveres dos usuários da saúde", Art. $4^{\circ}$ "Toda pessoa tem direito ao atendimento humanizado e acolhedor, realizado por profissionais qualificados, em ambiente limpo, confortável e acessível a todos".

O Centro de Saúde é o local onde se prestam serviços referentes à atenção básica. Assim, trata de muitas pessoas que compõem parte da população de um município. Para se projetarem edificações que estejam aptas a receber estas funções, o Manual de Estruturas Físicas das Unidades Básicas de Saúde (UBS) atenta para a importância da concepção arquitetônica das UBS, de modo que se integre ao entorno, de acordo com os valores da comunidade local, que o acesso seja facilitado e que a identificação das unidades seja clara.

O Ministério da Saúde (MS), com foco na melhoria assistencial, lança um novo sistema como forma de reorganização das UBSs já existentes, para que se tenha uma interação maior com os usuários, pois agora, muitos dos diagnósticos que eram apenas encaminhados para outras instituições especializadas são assistidos na própria unidade do início ao fim do tratamento. No entanto, essa estratégia não implica em novas construções, apenas em adaptações, quando necessárias.

Diante dessas mudanças no âmbito hospitalar, principalmente os que integram o setor público, a pesquisa justifica-se levando-se em consideração que expandir e qualificar a Atenção Básica $(A B)$ é um dos objetivos do Ministério da Saúde (MS) atualmente, além de que a Cidade de Cajazeiras, em seus últimos tempos, expandiu-se em grande escala, sendo que a área conhecida por 
Loteamento das Palmeiras carece deste tipo de equipamento público, obrigando a população a se descolocar em busca de atendimento a outras UBSs localizadas nos demais bairros, de modo que são encontrados em mínimas condições de salubridade, funcionalidade e segurança, apresentando-se, assim, com baixa qualidade no que tange a ambiência.

Desta forma, o projeto tem como objetivo geral apresentar um anteprojeto de uma Unidade da Saúde da Família (USF) na cidade de Cajazeiras adaptado ao clima quente e seco, tendo-se como base as normativas RDC $n^{\circ}$ 50/2002 e a NBR 9050/2015, o código de obras municipal de Cajazeiras e o manual de Sistema de Apoio à Elaboração de Projetos de investimentos em Saúde do Ministério da Saúde de 2011.

A escolha do tema partiu, primeiramente, do interesse pessoal do pesquisador do trabalho sobre Arquitetura Hospitalar e Conforto Ambiental, tendo em vista as questões ambientais que já são realidade tratada na Arquitetura e no Urbanismo, mas que ainda estão pouco empregadas no setor hospitalar.

Dentre vários problemas ambientais enfrentados hoje, a seca é o fenômeno que castiga principalmente o sertão paraibano, região nordeste, que necessita de tratamento adequado em todas as suas áreas, mas o gasto energético e poluição também são segmentos que precisam ser tratados. Importante, ainda, faz-se considerar que as edificações hospitalares são responsáveis por metade do total do consumo anual de energia e pela emissão de gases do efeito estufa. Os efeitos destes problemas podem ser amenizados através da construção civil, por meio de técnicas e soluções projetuais que visem, com relação a energia, a sua geração e a seu menor consumo, e com a água, melhor aproveitamento e suporte para armazenamento. 


\section{METODOLOGIA}

Trata-se de uma pesquisa exploratória, aplicada. A abordagem do tratamento da coleta de dados da pesquisa será qualitativa, pois busca fonte direta para coleta de dados, interpretação de fenômenos e atribuição de significados.

A priori, foi realizada a pesquisa bibliográfica, visando a discorrer sobre o tema do estudo, sendo realizada com base na utilização de materiais já elaborados: livros, artigos científicos, revistas e documentos na busca e alocação de conhecimento sobre a Arquitetura Hospitalar acerca do histórico, entendimento e funcionamento do serviço.

A segunda etapa consistiu na realização de visitas técnicas para as observações in loco, levantamento fotográfico e planimétrico, em duas unidades de saúde da família ou postos de saúde ativos, disponíveis no município de Cajazeiras.

O terceiro fator constitui-se da recorrência da Análise de Geoffrey Baker (1998), método amplamente utilizado por arquitetos e profissionais ligados a projetos, que, dentre vários fatores, utiliza-se de métodos e técnicas que revelam elementos positivos e negativos do ambiente, ressaltando pontos como: Genius loci, iconologia, identidade, significado de uso, plástica, geometria e estrutura (BELTRAMIN, 2015).

A quarta etapa consistiu na elaboração das diretrizes da proposta, que determinam a escolha do terreno e apresentam estudos iniciais com relação às características do terreno, quanto à dimensão da área, entorno, acessos e a incidência solar, sendo este último utilizando informações do programa Analysis SolAr 6.2. É estabelecido também o programa de necessidades e fluxograma baseado nas normativas RDC n50/2002 e Somasus, do MS.

Neste quesito, foi exposto o processo projetual, que apresenta o conceito e partido arquitetônico, sendo que o conceito é a ideia principal que o autor da obra pretende transmitir através da plástica do edifício e o partido arquitetônico refere-se às decisões projetuais tomadas pelo arquiteto para demonstrar o conceito, sendo apresentada também a área de implantação, zoneamento e acessos. 
Nesta última etapa, apresentou-se o memorial descritivo, que aponta as decisões tomadas quanto à estrutura, circulação vertical, vedações e revestimentos internos e externos, soluções referentes ao conforto e, por fim, a exibição do resultado formal.

\section{RESULTADOS E DISCUSSÃO}

A USF São Francisco e a Amélio Estrela Dantas Cartaxo estão comportadas no mesmo edifício, localizado na rua Vitoria Bezerra, no Bairro São Francisco, na zona sul da cidade. No entorno, há predomínio de edificações com até dois pavimentos, do tipo residenciais e pequenos comércios.

A fachada é simples, pintada de branco, o que denota que o responsável pela edificação teve uma maior preocupação com a funcionalidade dos espaços que caracterizam sua estética que incluiu elementos construtivos como os cobogós.

Neste edifício, adotaram-se algumas estratégias que beneficiaram os ambientes, como o uso de cobogós de teto nos pátios internos com o propósito de impedir a incidência solar direta, permitindo que o espaço permaneça mais tempo com sombra sem bloquear a passagem de luz e ventilação natural.

Quanto à estrutura, podem-se constatar os seguintes aspectos: acabamentos sem manutenção com diversas rachaduras; as salas climatizadas sem o devido tratamento para instalação principalmente com relação às vedações das janelas; e as instalações elétricas e luminosas são insuficientes. Aspectos estes que qualificam o espaço como impróprio para a assistência médica, pois estes aspectos dificultam o trabalho dos profissionais.

A USF Dr. José Jurema está localizada na rua Leonardo Rolim, Bairro dos Remédios, zona oeste da cidade, onde atua uma equipe de profissionais de AB. Em seu entorno, existem diversos comércios, com predominância de edificações residenciais.

O estabelecimento está dentro de um terreno com $241,85 \mathrm{~m}^{2}$ e, em seu interior, aparecem implantadas: uma sala médica, uma odontológica, uma de 
enfermagem, uma de vacina, uma de triagem e outra de curativos, contando também com recepção, copa, banheiro coletivo e quintal, de modo que, para um melhor entendimento, foi elaborado um estudo de manchas.

Quadro 01 - diagnóstico das UBS São Francisco, Amélio Estrela Dantas Cartaxo e Dr. José Jurema.

\begin{tabular}{|c|c|}
\hline $\begin{array}{c}\text { USF São Francisco e a Amélio Estrela } \\
\text { Dantas Cartaxo }\end{array}$ & $\begin{array}{c}\text { Unidade de Saúde Familiar Dr. José } \\
\text { Jurema }\end{array}$ \\
\hline $\begin{array}{c}\text { Figura 1 - Acabamentos (Sala de } \\
\text { esterilização). }\end{array}$ & $\begin{array}{c}\text { Figura 2 - Acabamentos (Sala de } \\
\text { enfermagem). }\end{array}$ \\
\hline Fonte: Informações da pesquisa, 2019. & Fonte: Informações da pesquisa, 2019. \\
\hline Figura 3 - Vedações (Consultório \\
médico).
\end{tabular}


Figura 5 - Instalações elétricas e luminosas (Recepção).

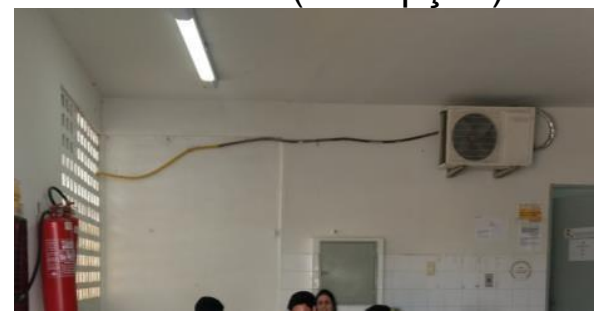

Fonte: Informações da pesquisa, 2019.
Figura 6 - Instalações elétricas e luminosas (sala enfermagem e arquivo).

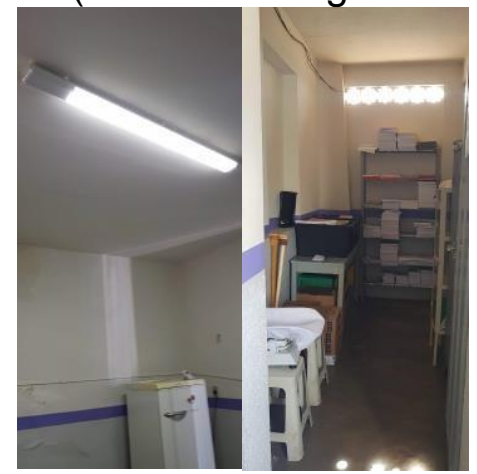

Fonte: Informações da pesquisa, 2019.

A escolha pelo município de Cajazeiras partiu da relação de proximidade do autor com a área de estudo, o que viabilizou uma coleta de dados mais concreta da proposta de implantação. A cidade conta com o suporte de dois hospitais públicos, sendo um destinado ao atendimento infantil, o Hospital Universitário Júlio Bandeira e o Hospital Regional de Cajazeiras. Conta, também, com um Hemonúcleo; uma Unidade de Pronto Atendimento, e ainda com 23 Centros/Unidades Básicas de Saúde (UBS), difundidas nos bairros da cidade e nas zonas rurais.

Sabendo que cada USF está disposta a atender o número máximo de 4.500 pessoas, é percebido que o número de unidades implantadas na região supre a necessidade com base em números. O ponto crucial para a escolha do terreno foi sua localidade, priorizando as áreas que possuem a falta desses tipos equipamentos. Para uma melhor visibilidade, foi realizado o mapeamento dos equipamentos públicos que prestam serviços de saúde e o Hemonúcleo, presentes na cidade de Cajazeiras.

Percebeu-se que a Zona Leste, mais precisamente o Loteamento Loteamento Imperial Residence, é uma área que está dentro da zona de expansão da cidade e não possui nenhuma UBS, tendo a USF Nilson Lopes, B. Cristo Rei como a mais próxima, porém, faz-se necessário um grande deslocamento para se chegar até ela, sendo necessário um transporte, utilizando-se a BR-230 PB no decorrer do trajeto.

O terreno escolhido está localizado no Loteamento Imperial Residence, possuindo como limite norte o Loteamento Urbano Alpha, a sul o Loteamento Santa Maria, a leste Loteamento Vale das Palmeiras e a oeste o Loteamento Parque 
Rosina Parente. No entorno, predominam edificações do tipo residencial, com um ou dois pavimentos.

O formato do lote é trapézio retângulo compreendendo uma de área de $1.560,12 \mathrm{~m}^{2}$, sendo que sua topografia é plana. O terreno está envolto ao norte medindo 30,00m (trinta metros) para a Avenida Projetada C, a sul medindo 30,00m (trinta metros) para a rua Jairo Borges, a leste medindo 52,00m (cinquenta e dois metros) e a oeste medindo 52,00m (cinquenta e dois metros) para a Rua Projetada H. Visto que a avenida irá demandar maior fluxo, é determinado que a fachada norte será o acesso principal e as demais como acessos secundários, sendo utilizado para acesso-de menor circulação, como de funcionários ou carga e descarga.

Figura 7 - Acessos.

\section{LEGENDA:}

ÁREA.VERDE.

TERRENO

ESCOLHIDO-

EDIFICAÇÕES

ACESSO- PRINCIPAL

ACESSOS- SECUNDÁRIOS

-

Fonte: Elaborado pelo autor.

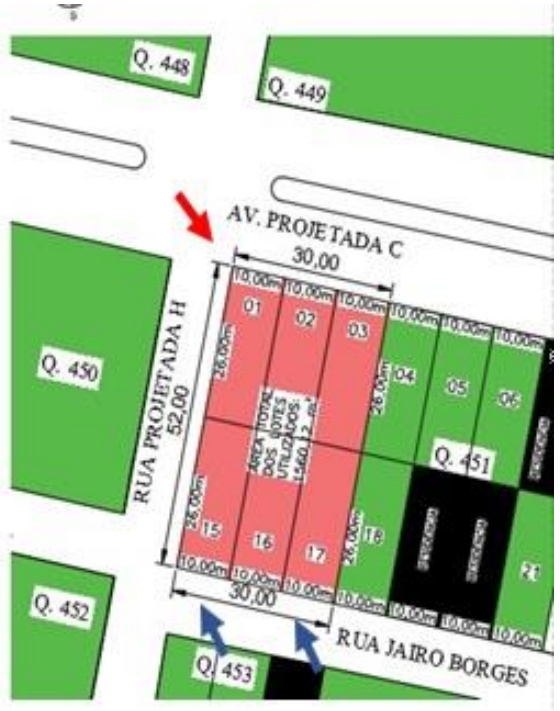

Devido à não obtenção da carta solar referente a Cajazeiras, foi utilizada a do Distrito de São Gonçalo a cerca de $29 \mathrm{~km}$ de distância de Cajazeiras como sendo o local mais próximo disponibilizado pelo programa Analysis Sol-Ar 6.2. Pelas simulações solares (figura 8) geradas sobre a fachada poente entre os solstícios e equinócios no período do início da manhã e fim da tarde, através do software Sketshup, constatou-se que no solstício de verão e no equinócio de primavera, recebe-se a maior parte da insolação; já no solstício de inverno e equinócio de 
outono, ocorre com menor frequência durante os horários do início da manhã ao fim da tarde.

As estratégias adotadas para as fachadas são a utilização de brises em madeira para proteção das janelas e a escolha por vegetação do tipo "Pata de Vaca", o que proporcionou o sombreamento para as fachadas. Sobre esse tipo de vegetação, Patro (2014) diz que "alcança de 6 a 12 metros de altura, mas raramente passando de 10 metros. Sua ramagem é esparsa, ramificada e, formando uma copa cheia e ampla na primavera e verão, fornecen boa sombra. No outono, perde gradativamente as folhas, sem, no entanto, ficar totalmente despida".

Para a elaboração do programa de necessidades da USF de Cajazeiras, baseia-se na legislação, utilizando as recomendações do Regulamento Técnico para planejamento, programação, elaboração e avaliação de projetos físicos de estabelecimentos assistenciais de saúde - RDC n 50/2002 e o manual de Sistema de Apoio à Elaboração de Projetos de investimentos em Saúde (Soma SUS, Ministério da Saúde, 2011).

É importante ressaltar que algumas Unidades de Saúde estão em estado antigo de conservação e que, para atender as novas realidades da ESF, estão sendo realizadas algumas adaptações, que são incapazes de prestar um serviço de qualidade, devido à capacidade do edifício e por deficiências encontradas. Por adotarem esse modelo, o autor considera impraticável a reforma destas unidades.

Dentre as diversas soluções realizadas durante a fase projetual, definem-se o conceito e o partido arquitetônico. Segundo Silva (1998), o conceito está relacionado àideia principal que o autor da obra pretende transmitir através da plástica do edifício.

Diante disso, o conceito da USF Riacho da Curicaca é a própria "Curicaca e seu habitat". Habitat cujo riacho perpassa pelo loteamento Imperial Residence (figura 8). 
Figura 8 - Localização do Riacho da Curicaca com marcação da proposta.

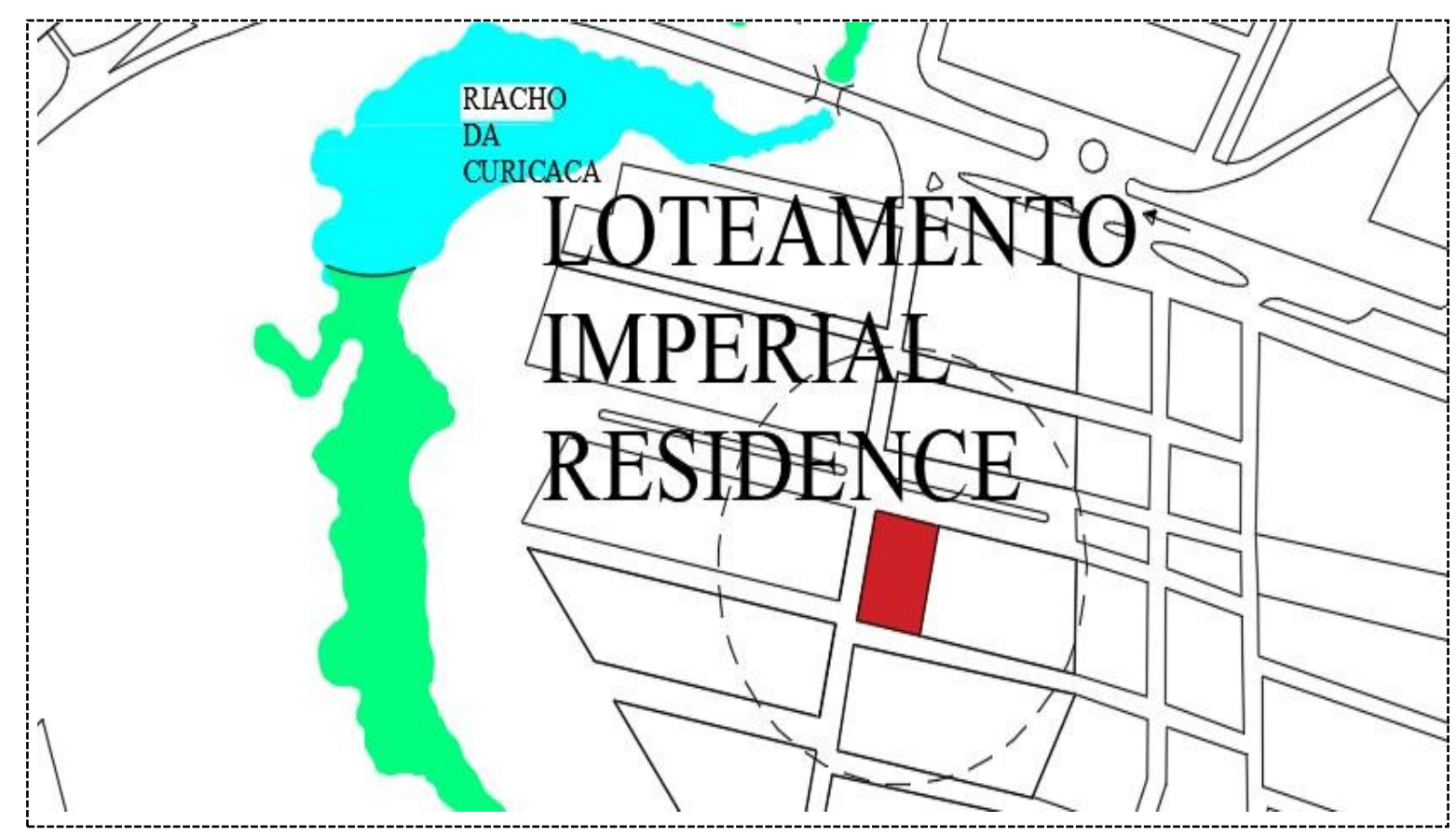

Fonte: Elaborado pelo autor. 2019.

Este lugar foi em algum tempo da história palco que propiciou, além da beleza natural, momentos memoráveis de bem estar, talvez os melhores, que as pessoas já viveram, diz um comentarista na publicação de Moreira (2013), e a Curicaca que deu nome ao riacho é uma ave com bico em forma de foice e com cauda curta, que habita locais com riachos. Contudo, a ideia principal parte do formato da Curicaca, cujas linhas sinuosas compõem a coberta da edificação.

O partido arquitetônico deu-se através da utilização de telhado verde, jardins verticais, brises e revestimentos externos que buscaram representar elementos da natureza em que vive a Curicara, bem como atender as soluções de conforto ambiental proposto inicialmente no projeto. Além disso, visando a atender aos objetivos de bem-estar dos usuários, incorporaram-se áreas verdes na parte interna e externa do edifício, que procuram proporcionar a humanização e contato com a natureza.

A implantação deu-se de forma transversal, ocupando cerca de $30 \%$ do terreno com área edificada. O imóvel é formado por dois blocos térreos que facilitam 
a acessibilidade. A adoção por um partido transversal atribuiu-se: a) Ao recebimento da ventilação predominante por todos os ambientes; b) À Redução do recebimento direto da insolação predominante; c) à redução no tempo de fluxo dos usuários; d) Ao contato com as áreas verdes; e) À dimensão do terreno.

As maiores fachadas estão dispostas nas direções leste e oeste, o que levou a adotar brises nas esquadrias para proteger estas fachadas contra a incidência solar. As esquadrias em vidro foram pensadas para proporcionar, além de soluções de conforto térmico, o contato do interno com as praças externas, permitindo a integração entre interno e externo.

O estacionamento foi disposto de acordo com a normativa RDC n`50/2002, contendo 10 vagas para carros, sendo uma destinada a idosos, uma a portadores de deficiência e uma para a ambulância. $O$ acesso às vagas comuns deste estacionamento dá-se através da Rua Jairo Boges, para a vaga de idosos e portadores de deficiência, pela Av. Projetada $C$ e para a vaga da ambulância, pela Rua Projetada H. Nesta última rua citada, foram locadas 14 vagas para motocicletas.

As vias de acesso são de mão dupla e as vagas de estacionamento comuns estão dispostas de forma transversal, com inclinação $45^{\circ}$ como forma facilitadora para entrada e saída dos veículos, as demais vagas estão de forma perpendicular à via. As vagas para veículos possuem dimensões de $2,50 \times 5,00 \mathrm{~m}$, sendo que a vaga para pessoas com deficiência possui espaço reservado para a circulação de 1,20 de largura. A vaga para ambulância possui dimensão de $3,00 \times 7,50 \mathrm{~m}$ e a para a vaga de motos $1,00 \times 2,50 \mathrm{~m}$. 
Figura 9 - Implantação

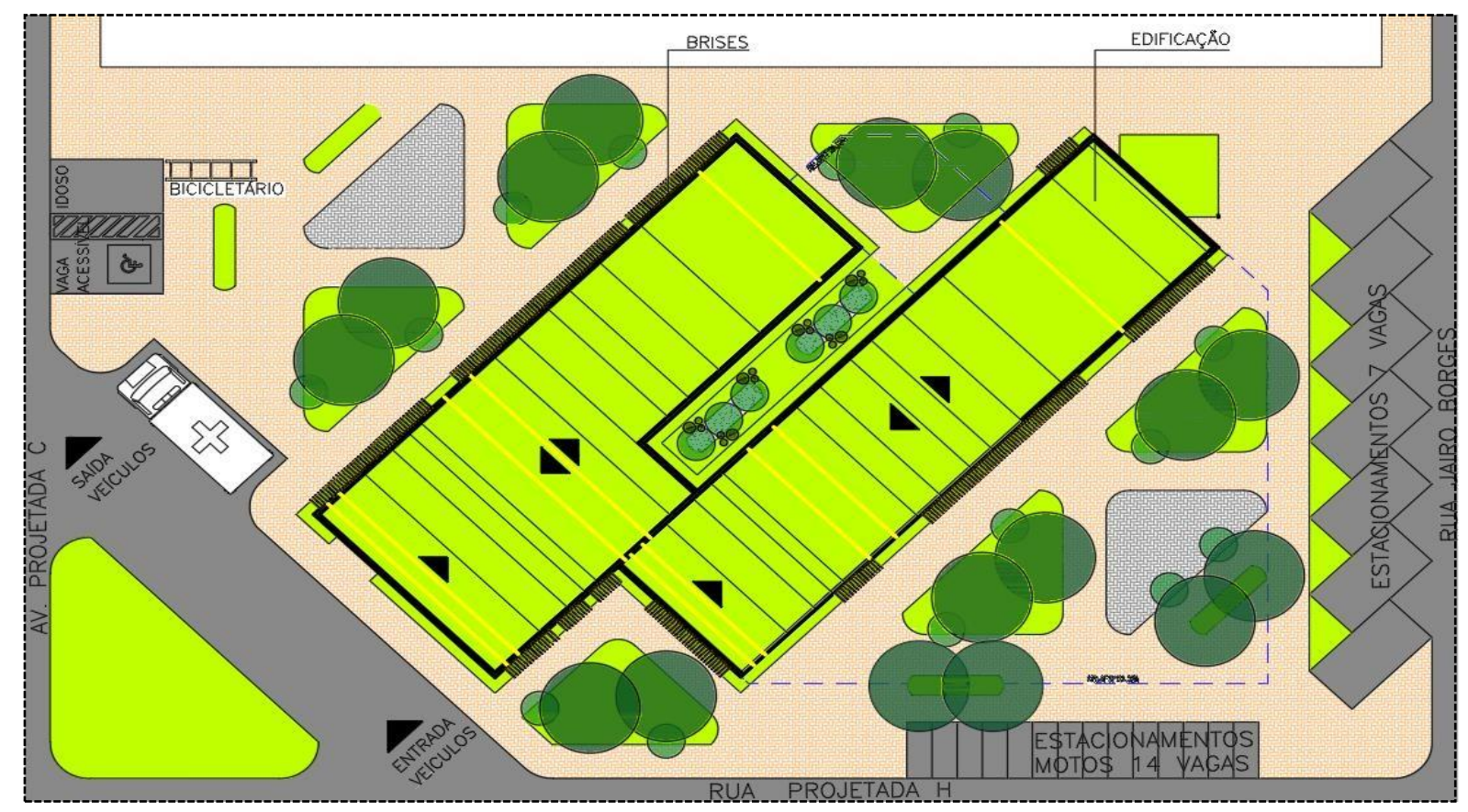

Fonte: Elaborado pelo autor, 2019.

A setorização foi implantada a fim de melhor dispor a relação do programa, os quais passaram por estudos de proximidade entre as unidades funcionais, de forma que melhor se agreguem os fluxos para melhor funcionamento dos equipamentos hospitalares. Juntamente a isso, definiu-se que as primeiras ampliações fossem dispostas também em térreo, a fim de continuar proporcionando a acessibilidade universal.

A setorização deu-se por meio do fluxo nas circulações, com o intuito de reduzi-lo e deixá-lo funcional. Definiram-se áreas de acesso rápido que foram dispostas o mais próximo do acesso principal possível, o setor administrativo em local que não interfira nos demais e que permita acesso secundário, e os consultórios pouco mais distante do acesso principal e próximos da administração, visto que estes locais são áreas mais delicadas devido ao grau em que os pacientes possam se encontrar, demandando menor fluxo e facilidade no acesso do corpo de funcionários para atender qualquer necessidade no setor administrativo. 
Figura 10 - Setorização

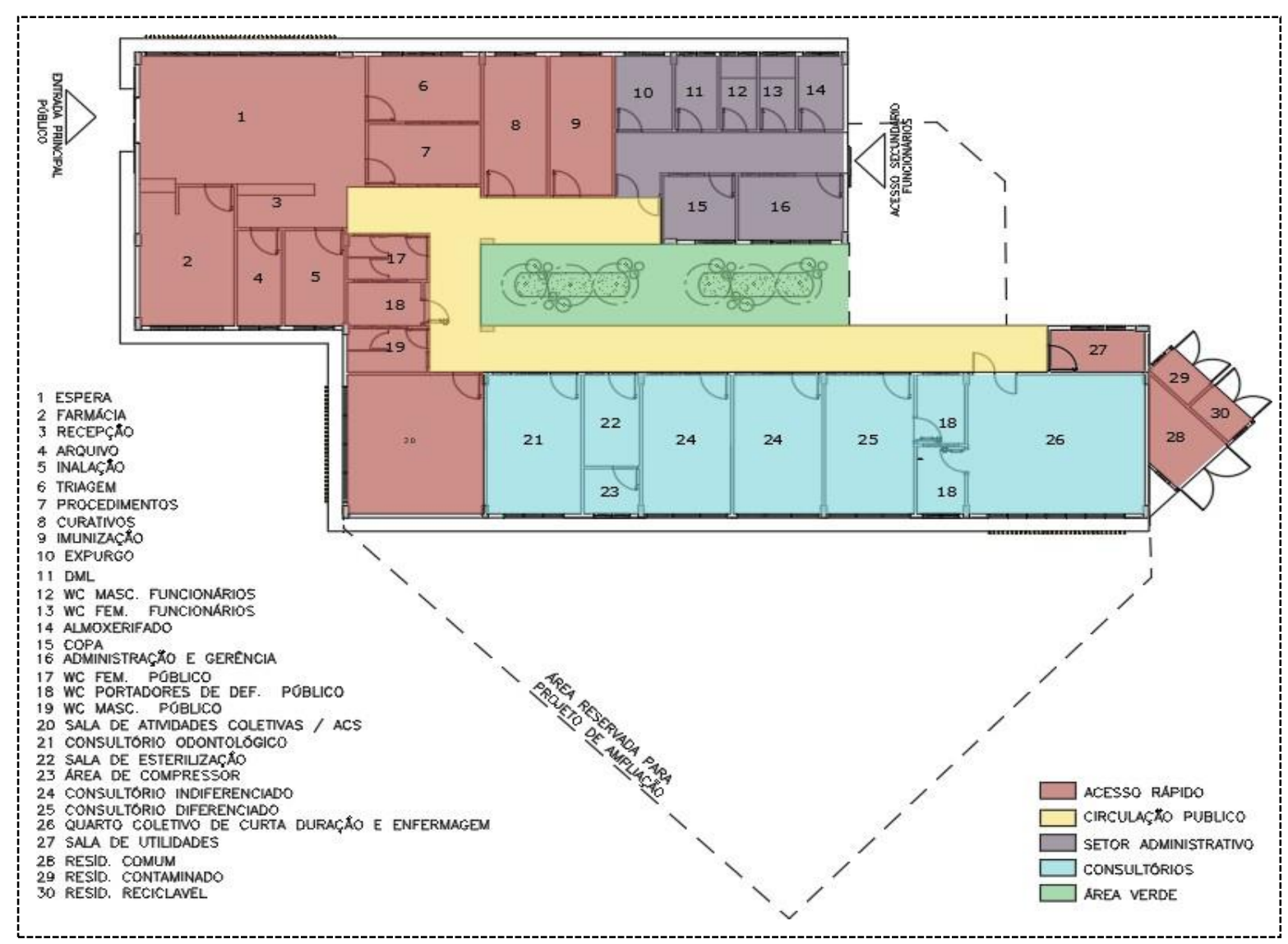

Fonte - Elaborado pelo autor, 2019.

As áreas de expansão foram pensadas de forma que possam dar continuidade funcional ao edifício, e que facilitem a promoção da acessibilidade universal. $E$ as áreas verdes internas têm como objetivo promover a humanização, de modo que o espaço possibilite o convívio e contemplação, oferecendo um melhor conforto aos usuários.

A USF Riacho da Curicaca é um equipamento público de saúde de porte I, localizada na cidade de Cajazeiras, interior da Paraíba, que irá prestar serviços ambulatoriais referentes à $A B$ para a comunidade cajazeirense, sendo a assistência seu principal objetivo. A necessidade deste tipo de equipamento evidenciou-se através da expansão da cidade e pela qualidade das unidades existentes, como abordado anteriormente. 
O estabelecimento comporta uma equipe de saúde formada por um médico, um enfermeiro, um auxiliar de enfermagem, de quatro a seis agentes de saúde e dois dentistas, de modo que pode assistir até 4.500 habitantes.

Para que o projeto obtenha mais fidelidade com o real, foi lançado o prédimensionamento e locação dos pilares que possuem espessura de $0,20 \mathrm{~m}$ por 0,45m dispostos em vãos de 6,93m como sendo o maior e 4,64m, o menor, que irão suportar a estrutura da coberta. Esta análise poderá ser revista e redimensionada com o projeto específico.

Para edificações que estão situadas na Zona Bioclimática 7, onde se encontra a cidade de Cajazeiras, a normativa RDC 15220/2003 - Desempenho térmico de edificações estabelece diretrizes construtivas. As escolhas foram tomadas a partir de dois critérios: a) Transmitância térmica: refere-se ao fluxo de calor que é transmitido para o interior do edifício; b) Atraso térmico: que consiste no atraso na transmissão de calor para o interior do edifício. Diante disso, as vedações externas acontecem por meio de uma parede com largura total de $27,00 \mathrm{~cm}$, estando formada por argamassa interna de $2,50 \mathrm{~cm}$, bloco cerâmico de $9,00 \mathrm{~cm}$, uma lã de rocha de $4 \mathrm{~cm}$, outro bloco cerâmico de $9 \mathrm{~cm}$ e argamassa externa de $2,50 \mathrm{~cm}$, e câmera de ar de $5,00 \mathrm{~cm}$. A escolha por este tipo de parede deu-se por ela possuir um atraso térmico de 6,3 horas e baixa transmitância de calor, o que promove um ambiente interno mais agradável que o exterior. 
Figura 11 - Parede externa.

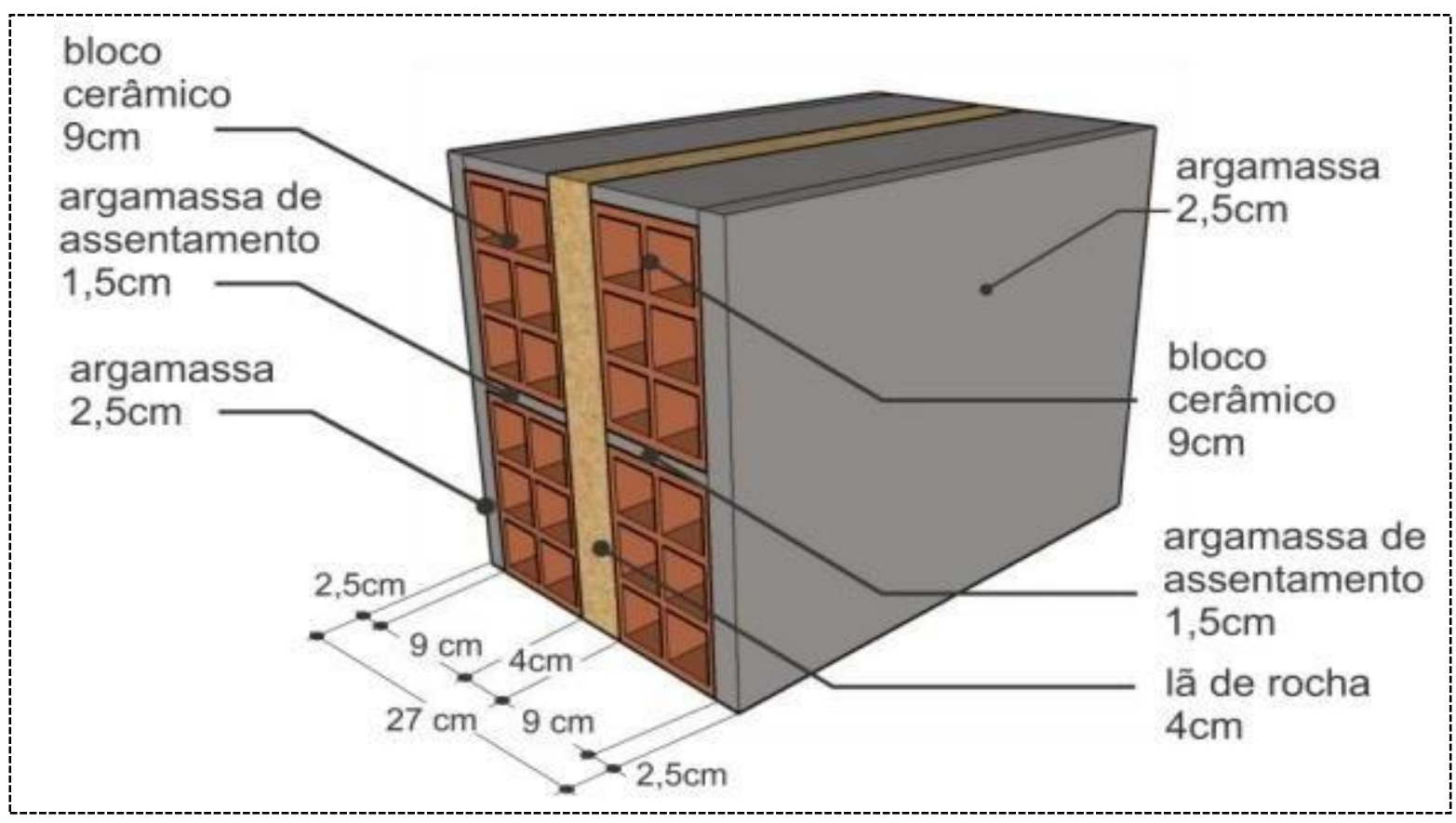

Fonte: portaria Inmetro $N^{\circ} 50 / 2013$. Catálogo de propriedades térmicas de paredes coberturas e vidros.

As paredes internas totalizam uma espessura de $9,75 \mathrm{~cm}$, sendo formadas por placa de gesso de $1,25 \mathrm{~cm}$, lã de rocha de $7,5 \mathrm{~cm}$ e placa cimentícia de $1,00 \mathrm{~cm}$. Optou-se por este tipo de parede devido a sua leveza, espessura, seu grau de desempenho acústico, que pode chegar a $47 \mathrm{~dB}$, sua resistência ao fogo que dura 30 minutos e sua resistência à umidade.

Com relação ao telhado, foi definida a instalação do sistema hidromodular de telhado vegetativo da empresa Ecotelhado, que consiste em uma camada de vegetação, uma membrana de absorção, módulo piso nuvem onde será armazenada a água para direcioná-la ao reservatório, módulo de galocha que se trata do impermeabilizante e a laje de concreto. 
Figura 12 - Corte esquemático do sistema hidromular.

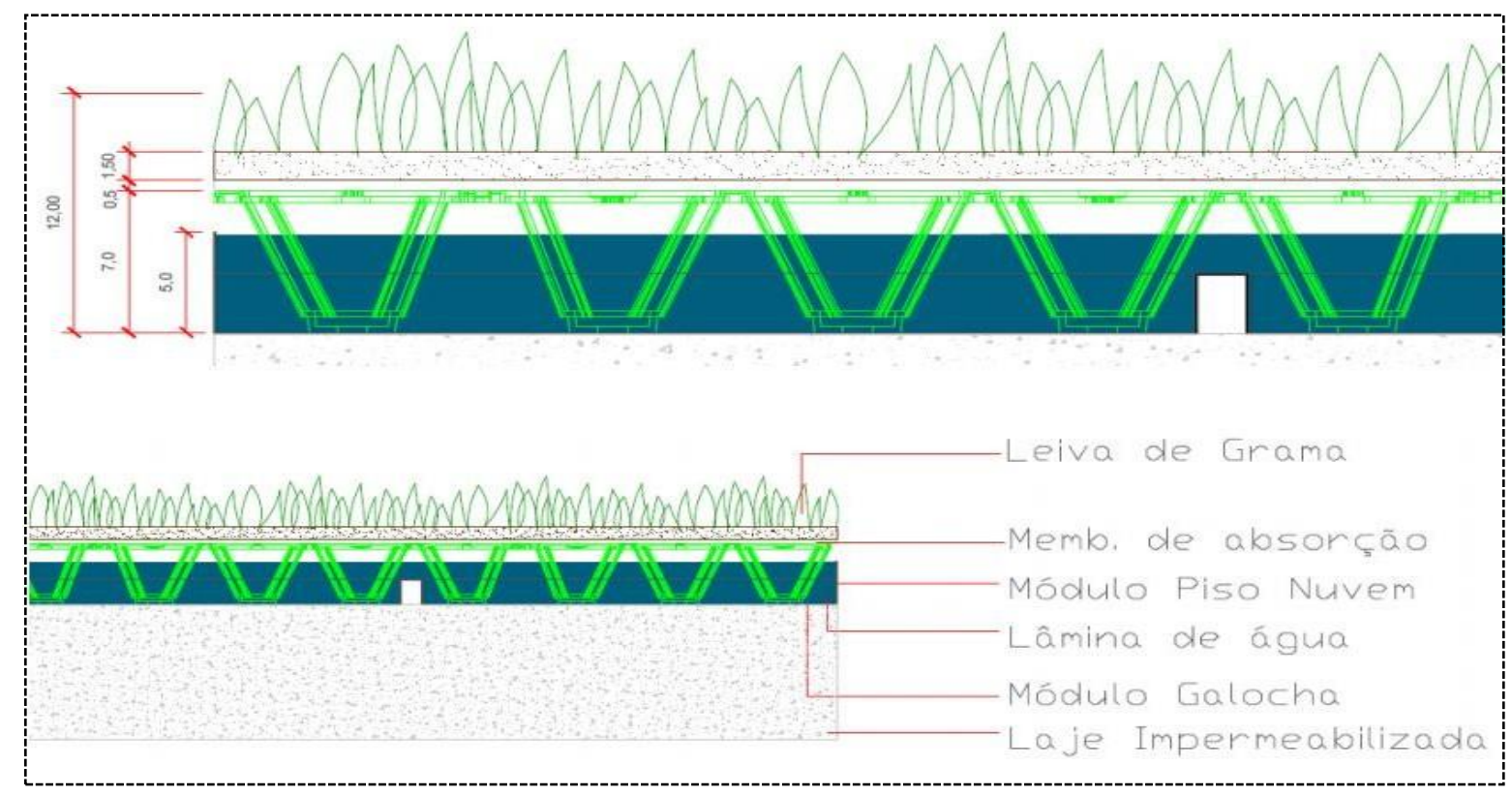

Fonte: Ecdotelhado, Telhado verde Hidromodular para coberturas. Disponível em: $<$ https://ecotelhado.com/sistema/ecotelhado-telhado-verde/hidromodular/>. Acessado em 15 de mai. 2019.

O telhado verde, além de compor quesitos estéticos e conceituais a que o partido arquitetônico se propõe, possui a função de promover um bom isolamento térmico, já que sua transmitância de calor é $1,88 \mathrm{~W} / \mathrm{m}^{2} \mathrm{k}$, e o atraso térmico, $6.4 \mathrm{~h}$, o que indica que este tipo de cobertura levará bastante tempo para transmitir calor ao interior do edifício, consequentemente, terá um ambiente agradável quanto ao conforto térmico e acústico para os ambientes internos. O forro será em placas de gesso acartonado, as janelas e algumas portas são compostas por metais e vidro, mas algumas portas internas são em MDF, sendo que as bandeirolas servem para que $o$ ar quente possa sair dos ambientes, que a ventilação natural possa percorrer por todo o edifício e que a iluminação natural seja fornecida.

Como se trata de um unidades de nível ambulatorial, a RDC n50/2002 sugere para as áreas semicríticas ${ }^{2}$ revestimentos que sejam resistentes à lavagem e ao uso de desinfetantes, sendo superfícies lisas e sem rachaduras para evitar o acúmulo de poeira e proliferação de fungos ou bactérias. 
Para apresentar o produto do projeto, seguem imagens de perspectivas da USF Riacho da Curicaca.

Figura 13 - Perspectiva 01.

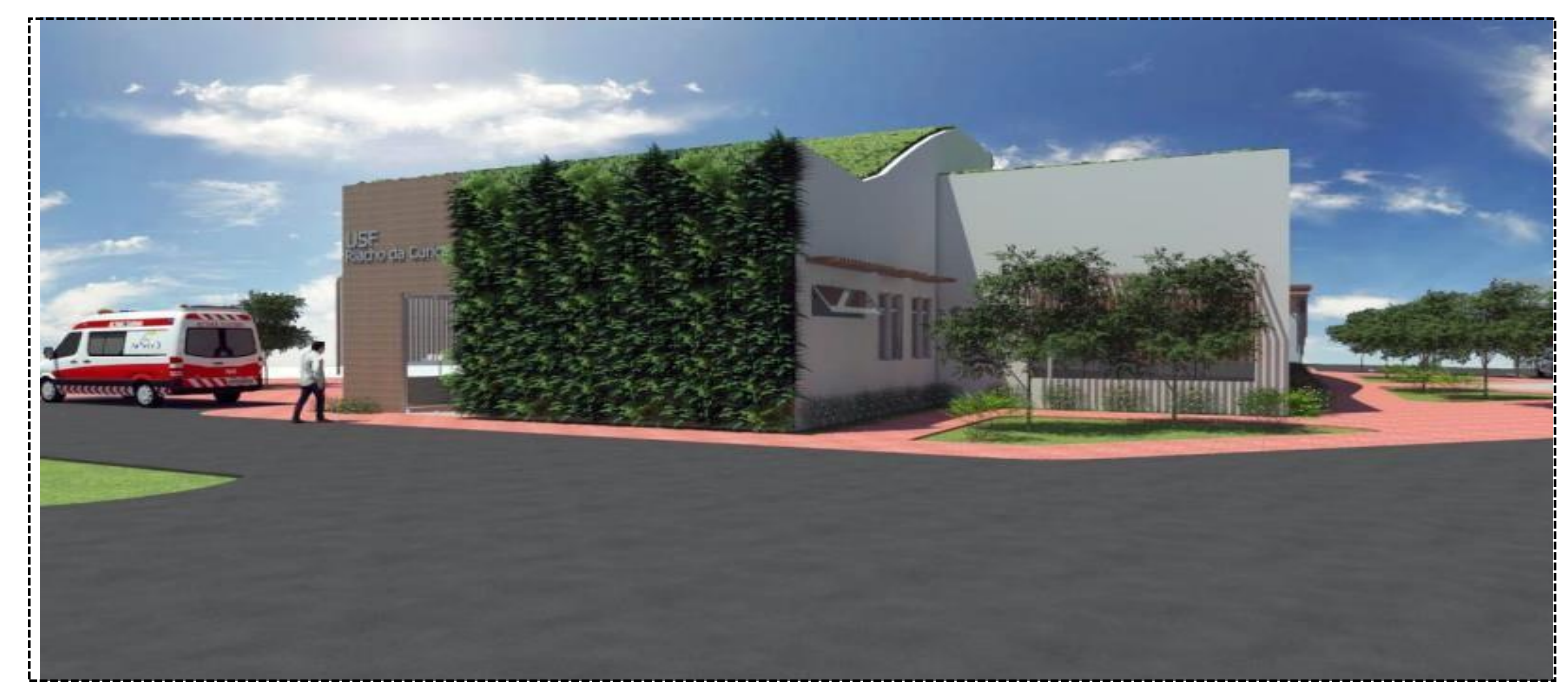

Fonte: produzido pelo autor, 2019.

Figura 14 - Perspectiva 02.

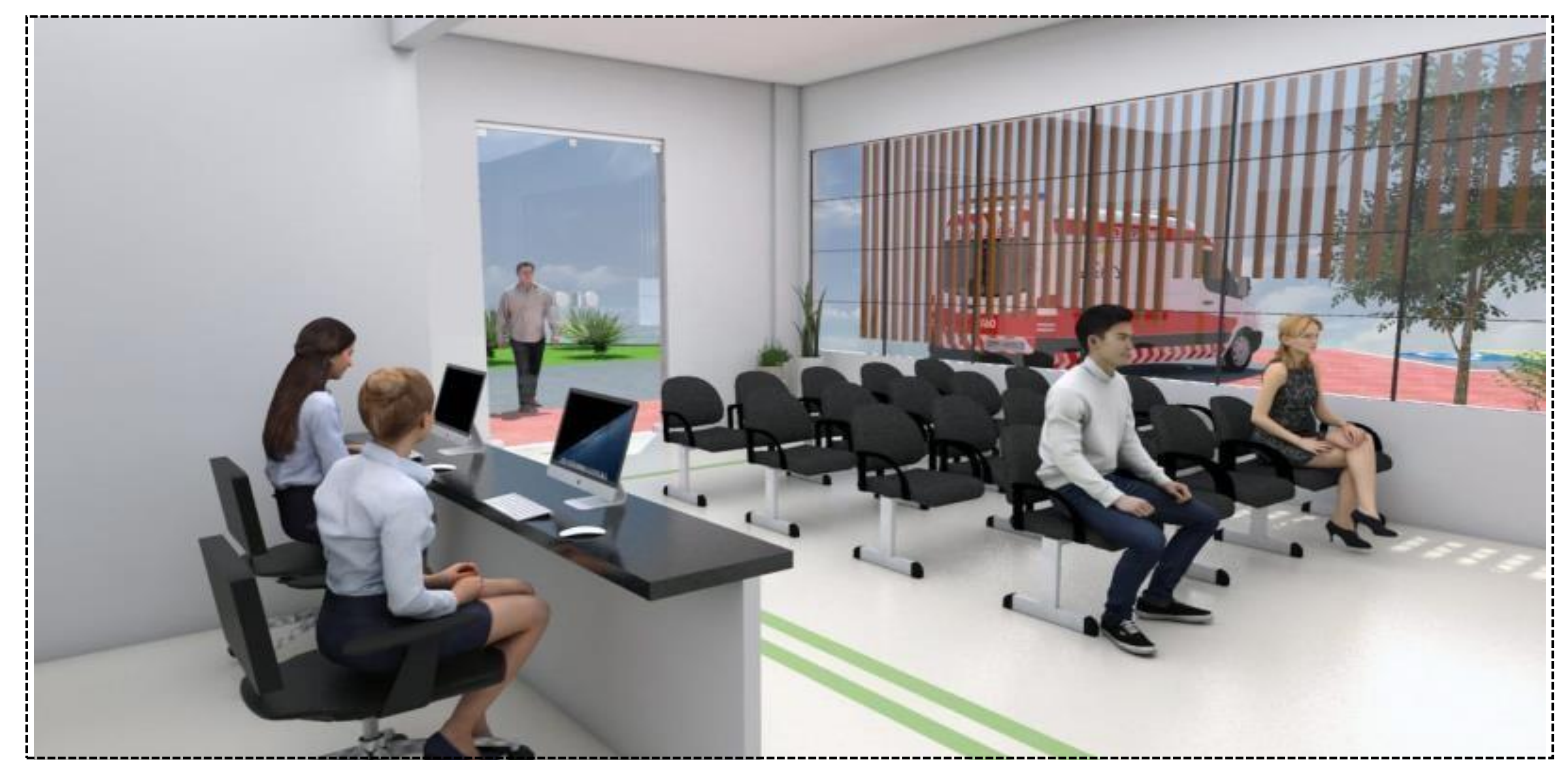

Fonte: produzido pelo autor, 2019. 
Figura 15 - Perspectiva 03.

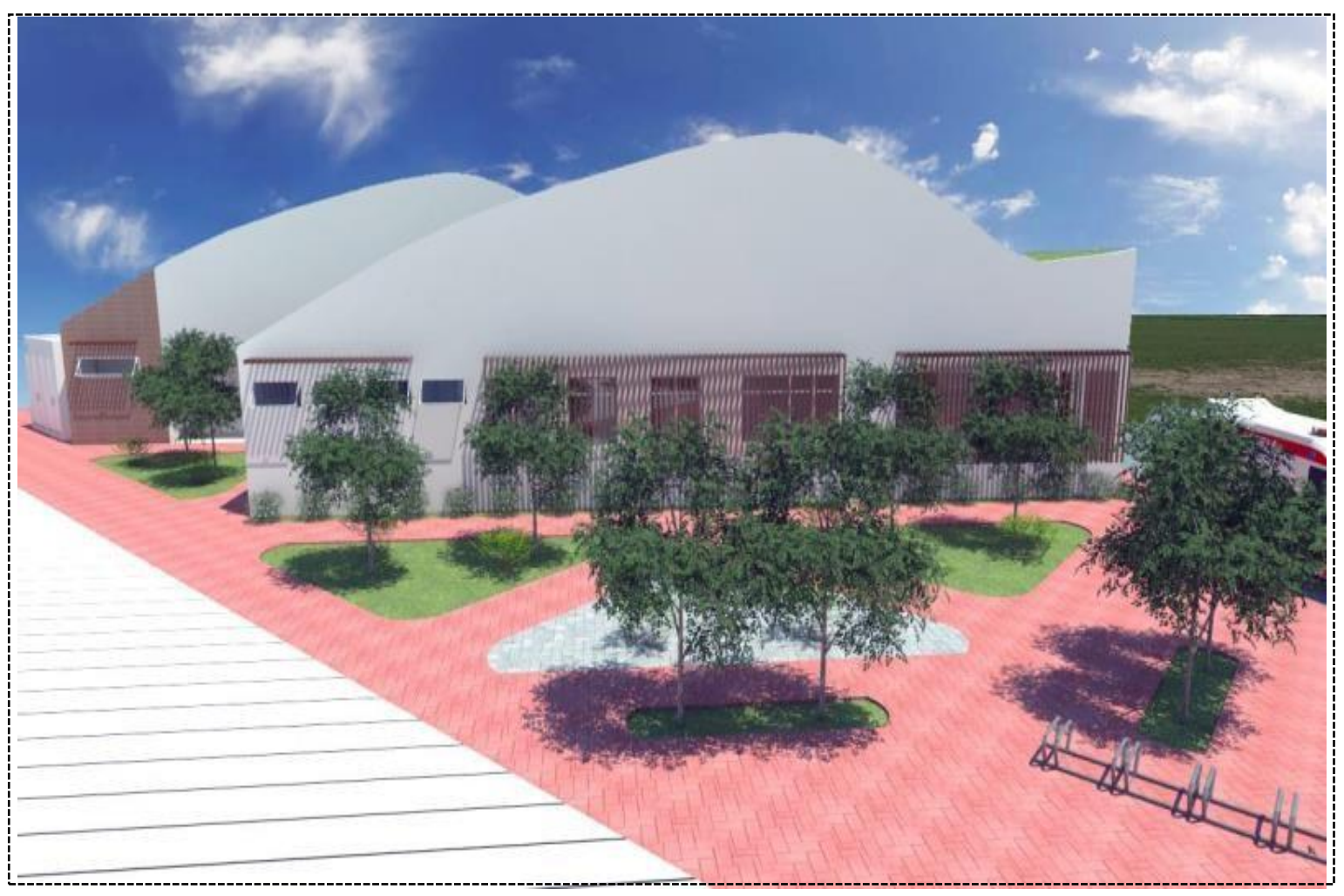

Fonte: produzido pelo autor, 2019.

Figura 16 - Perspectiva 04.

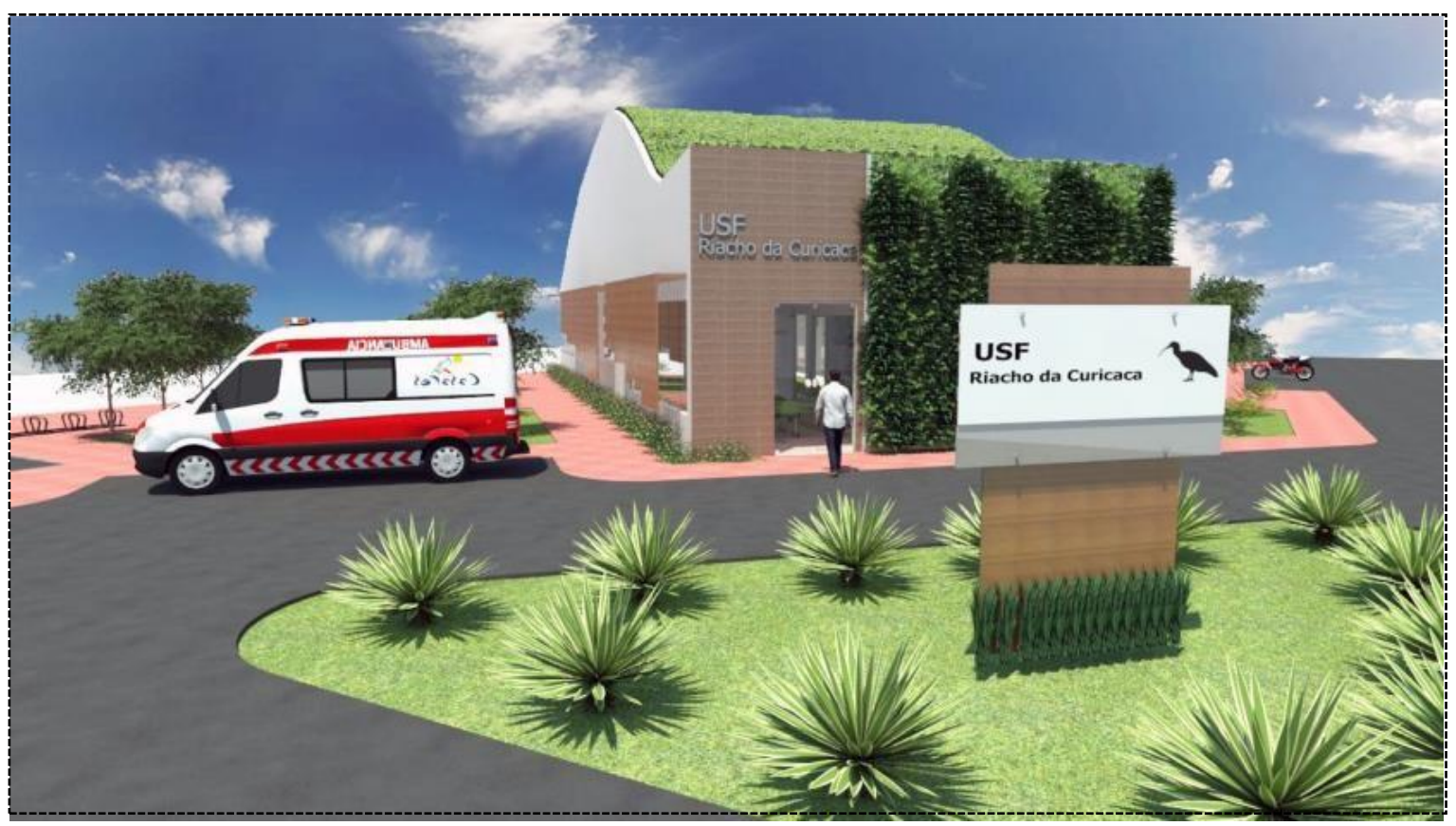

Fonte: produzido pelo autor, 2019. 
Figura 17 - Perspectiva 05.

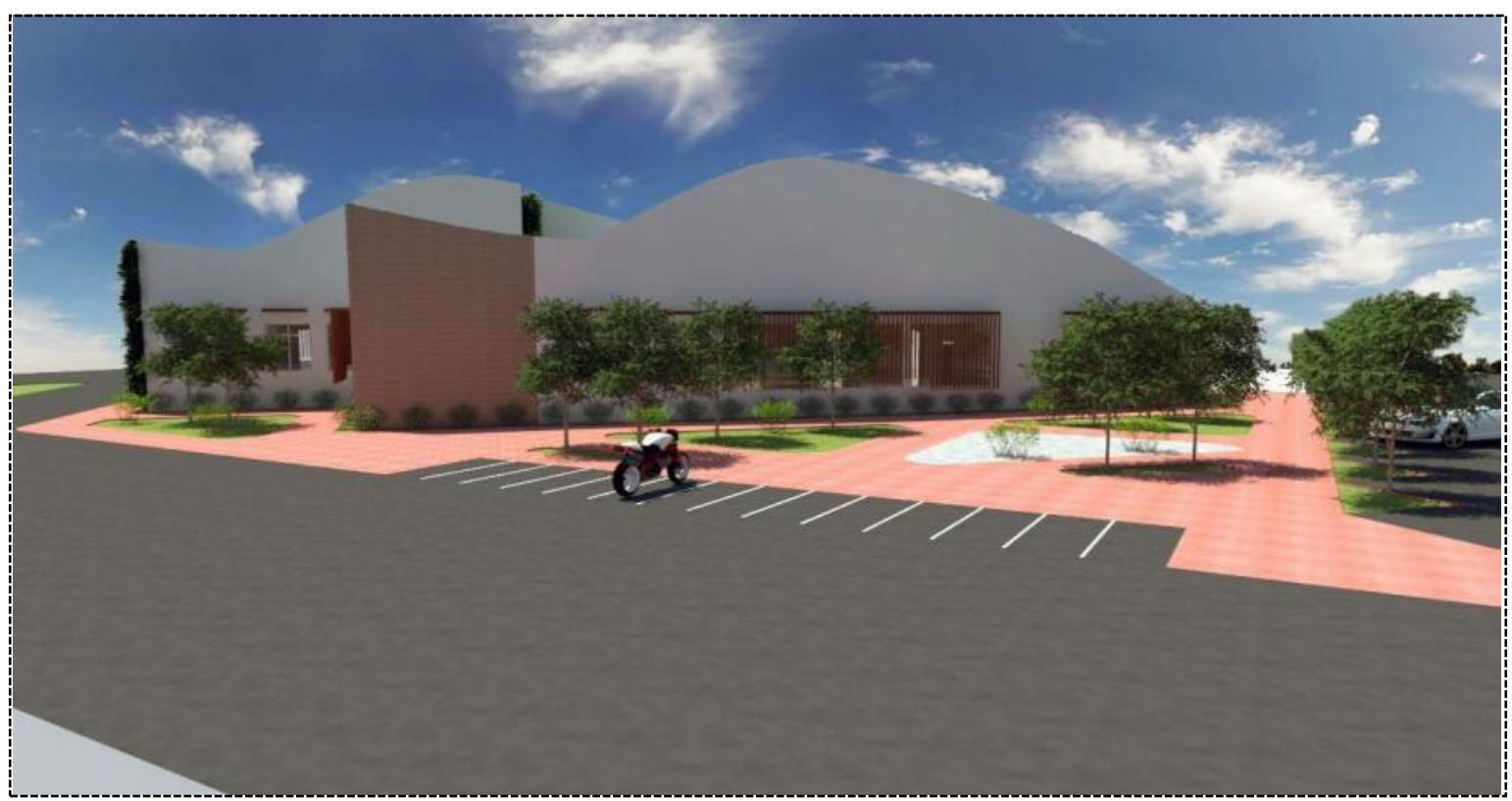

Fonte: produzido pelo autor, 2019.

Figura 18 - Perspectiva 06.

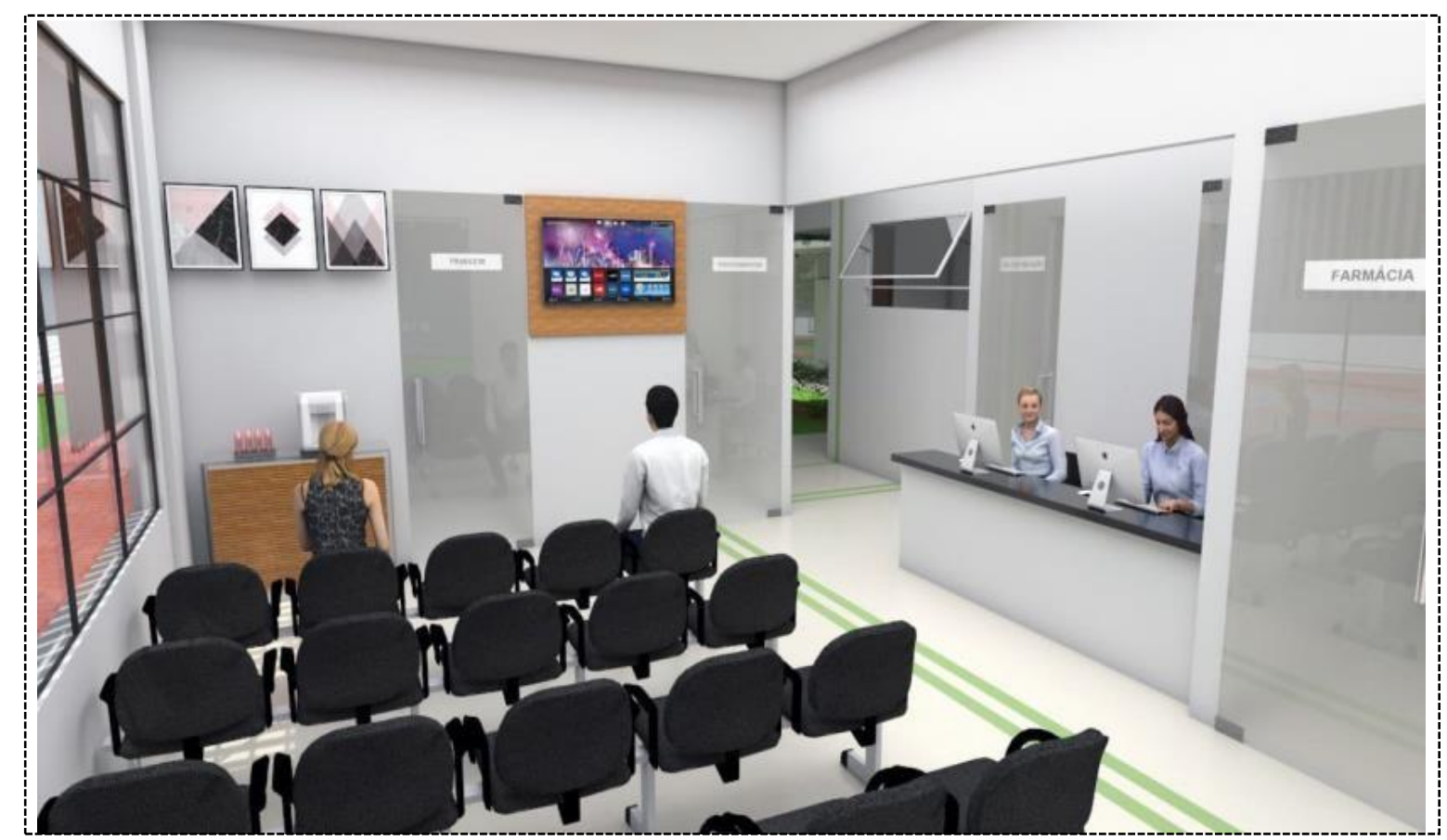

Fonte: produzido pelo autor, 2019. 
Figura 19 - Perspectiva 07.

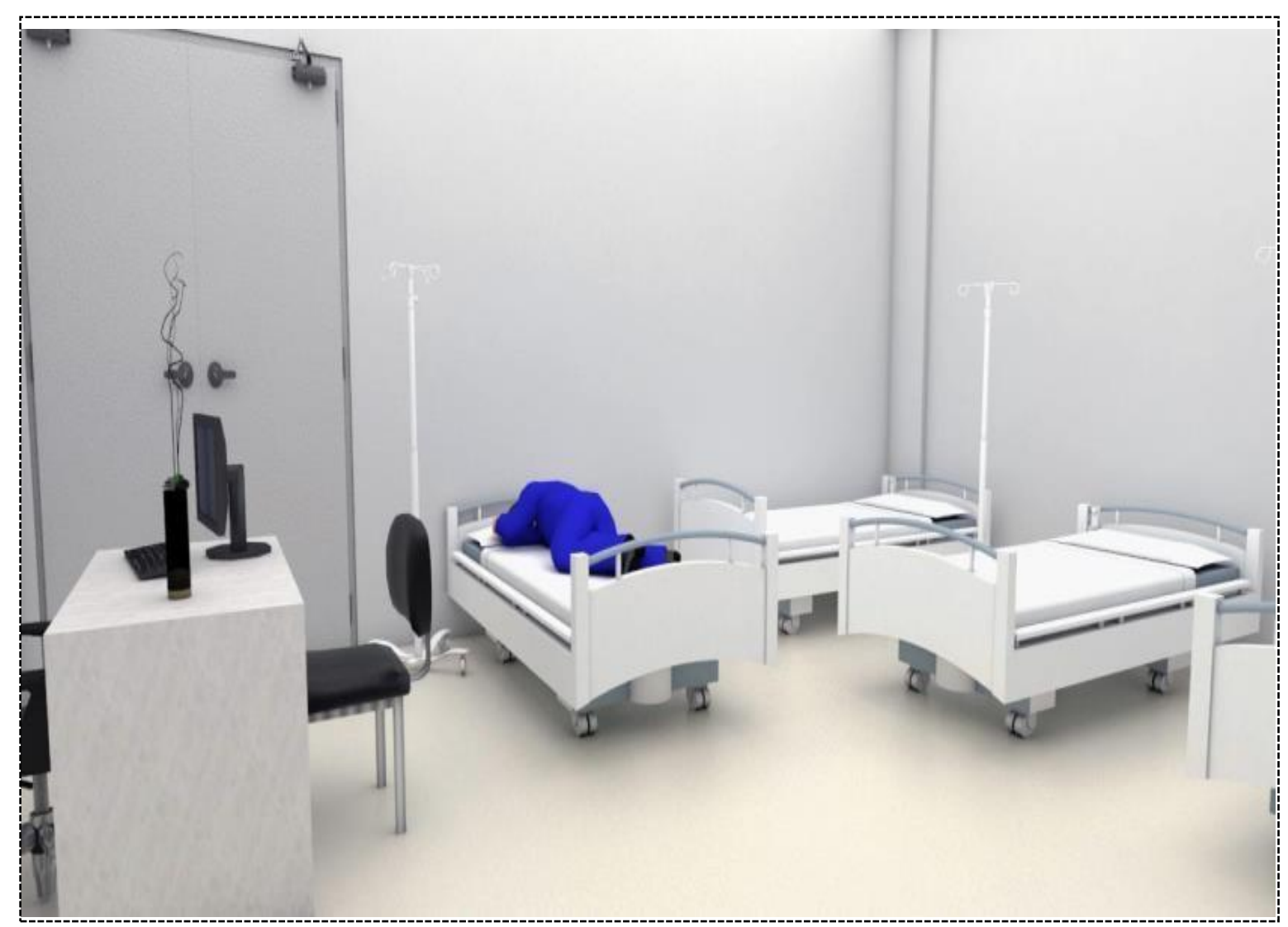

Fonte: produzido pelo autor, 2019.

Figura 20 - Perspectiva 08.

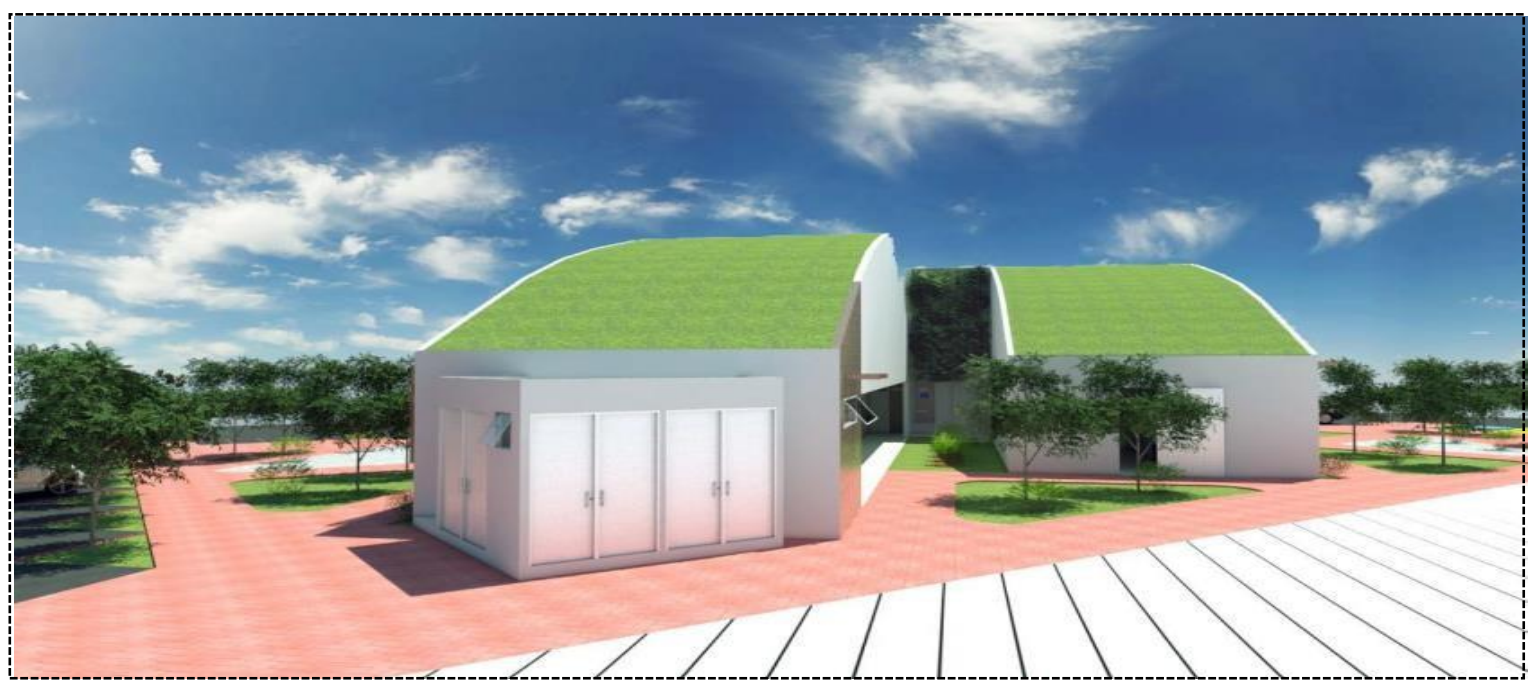

Fonte: produzido pelo autor, 2019. 


\section{CONCLUSÃO}

Após todos os procedimentos executados com excelência, o objetivo principal de elaborar uma proposta de anteprojeto de uma USF para o clima quente e seco em Cajazeiras-PB foi alcançado através da pesquisa bibliográfica, estudo das unidades existentes na cidade, análise de projetos correlatos; elaboração do processo projetual; e o resultado final. Buscou-se aplicar técnicas e soluções projetuais mais adequadas para o clima quente e seco; conhecer e empregar os parâmetros e exigências das normativas pertinentes ao tema; e demonstrar a real situação das unidades existentes, dessa forma, contribuindo como referência para projetos futuros dentro da ambiência hospitalar.

É importante ressaltar que projetar edifícios hospitalares representa um desafio devido à complexidade que as normativas exigem, referentes aos fluxos, acessos, interligações e programa de necessidades, incorporando-os a técnicas construtivas que proporcionem conforto e bem-estar aos usuários, o que demanda um trabalho minucioso. Por se tratar de um tema não abordado no decorrer do curso, exigiu-se um grande estudo através da literatura e um levantamento do cenário atual das UBS de Cajazeiras, para o entendimento das particularidades desse setor.

Desse modo, é imprescindível expor a gratificação que foi trabalhar com o tema arquitetura hospitalar e o local do projeto, por se tratar de uma região em que o autor pretende atuar futuramente como profissional relacionado ao tema. Entende-se que todo o aprendizado adquirido será utilizado no decorrer de sua carreira como Arquiteto e Urbanista quando formado.

Por fim, devido às particularidades que o tema aborda, sugerem-se estudos mais aprofundados quanto à percepção dos usuários que irão utilizar este equipamento, para que viabilizem, ainda mais, o conforto e bem estar através da psicologia ambiental. Mesmo se tratando de um tema muito específico, o autor considera-o imprescindível, já que se trata de ambientes que buscam a cura de doenças, e que não foram abordados neste trabalho por não serem o foco do 
objetivo proposto e pelo tempo para a realização do trabalho, mas que podem ser abordados por estudos futuros em outro momento.

\section{REFERÊNCIAS BIBLIOGRÁFICAS}

ASSOCIAÇÃO BRASILEIRA DE NORMAS TÉCNICAS, ABNT. NBR 9050: Acessibilidade a edificações, mobiliário, espaços e equipamentos urbanos. Rio de Janeiro, 2015.

NBR 15220: Desempenho térmico de edificações Parte 3: Zoneamento bioclimático brasileiro e diretrizes construtivas para habitações unifamiliares de interesse social. Rio de Janeiro, 2003.

BELTRAMIN, Renata Maria Geraldini, 1984, Bel Caracterização e sistematização de quatro modelos de análise gráfica: Clark, Pause, Ching, Baker e Unwin. Campinas, SP: [s.n.], 2015.

BRASIL, Portal da Saúde. Cronologia Histórica da Saúde Pública, 2017. Disponível em < http://www.funasa.gov.br/cronologia-historica-da-saude-publica>. Acesso em: 20 de nov. de 2018.

Portaria № 1.820, de 13 de agosto de 2009. Dispõe sobre os direitos e deveres dos usuários da saúde. Ministério da Saúde dispõe sobre as diretrizes e normas regulamentadoras de pesquisas envolvendo seres humanos. Conselho Nacional de Saúde. Disponível em: <http://bvsms.saude.gov.br/bvs/saudelegis/gm/2009/prt1820_13_08_2009.html >. Acesso em: 6 mai. 2018.

Art. 196, Constituição da República Federativa do Brasil de 1988. Dispõe sobre dos direitos sociais e individuais, a liberdade, a segurança, o bem-estar, o desenvolvimento, a igualdade e a justiça como valores supremos de uma sociedade fraterna, pluralista e sem preconceitos. Disponível em: <https://www.jusbrasil.com.br/topicos/920107/artigo-196-daconstituicao-federal-de-1988 >. Acesso em 07 mai. 2018.

$\begin{array}{lll} & \text { Ministério da Saúde, Norma Operacional Básica do Sistema Único de Saúde (NOB- } \\ \text { SUS), } & 1996 . & \text { Disponível }\end{array}$ <http://bvsms.saude.gov.br/bvs/saudelegis/gm/1996/prt2203_05_11_1996.html>. Acesso em 22 de outubro de 2018.

. Ministério da Saúde, Resolução-RDC № 50, de 21 de fevereiro de 2002. Disponível em: <http://bvsms.saude.gov.br/bvs/saudelegis/anvisa/2002/res0050_21_02_2002.html>. Acesso em: 05 de novembro de 2018.

em:

Ministério da Saúde, Resolução-RDC № 51, de 10 de outubro de 2011. Disponivel <http://portal.anvisa.gov.br/documents/10181/2954239/RDC_51_2011_COMP.pdf/e0720f17-

70fc-4eb8-b89f-acc025bdf661 >. Acesso em: 06 de novembro de 2018.

. Manual de Estruturas Físicas das Unidades Básicas de Saúde. Saúde da Família. Disponível em: <http://dab.saude.gov.br/portaldab/ape_requalifica_ubs.php $>$. Acesso em: 08 de mai. 2019.

CAJAZERIAS, Prefeitura Municipal de. Código de Obras e Urbanismo de Cajazeiras. Disponível em: <https://cajazeiras.pb.gov.br/transparencia/legislacao-municipal/> Acesso em: 15 de novembro 2018. 
IBGE, Brasileiro de Geografia e Estatística, Mapa Climatológico, 2016. Disponível em: <https://mapas.ibge.gov.br/tematicos>. Acesso em 16 de novembro de 2018.

Mapas mudos. Disponível em: <https://mapas.ibge.gov.br/escolares/mapasmudos.html>. Acesso em: 16 de novembro de 2018.

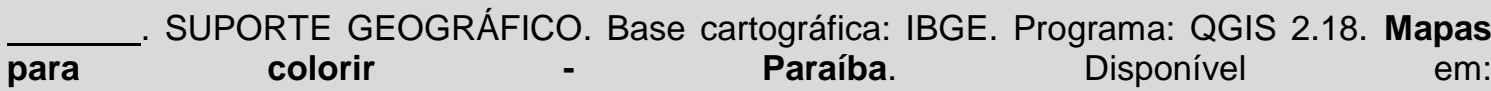
<https://suportegeografico77.blogspot.com/2018/02/mapas-para-colorir-paraiba.html>. Acesso em: 16 de novembro de 2018.

ECOTELHADO. Telhado verde Hidromodular para coberturas. Disponível em: <https://ecotelhado.com/sistema/ecotelhado-telhado-verde/hidromodular/>. Acesso em 15 de mai. 2019.

LAMBERTS, R.; DUTRA, L.; RUTTKAY P. Eficiência Energética na arquitetura. São Paulo: PW, 1997.

MOREIRA, Mariana Moreira. Ô menino, onde é a Curicaca, lá de Cajazeiras, Blog Sete Candeeiros, 2013. Disponível em: <http://blogsetecandeeiroscaja.blogspot.com/2013/10/omenino- onde-e-curicaca-la-de.html>. Acesso em: 25 de abr. de 2019.

O canto da Curicaca, Fazenda Santa Rita de Cássia, Mato Grosso do Sul, 2016. Disponível em: <https://www.youtube.com/watch?v=yfMFBxqo1Nw>. Acesso em 26 de abr. 2019.

PATRO, Raquel Patro. Pata-de-vaca - Bauhinia variegata, 2014. Disponível em: $<$ https://www.jardineiro.net/plantas/pata-de-vaca-bauhinia-variegata.html>. Acesso em: $11 \mathrm{de}$ junho de 2019.

PIRES, Fátima Pire. Primeiro hospital do Brasil. 2012. Disponível em: $<$ http://www.rankbrasil.com.br/Recordes/Materias/06VU/Primeiro_Hospital_Do_Brasil>. Acesso em: $22 / 11 / 2018$.

SILVA, Elvan. Uma introdução ao projeto arquitetônico. $2^{\mathrm{a}}$ edição. Porto Alegre: Editora da UFRGS, 2006.

WEBSITE METEOBLUE. Clima Cajazeiras. Disponível em: <https://www.meteoblue.com/pt/tempo/previsao/modelclimate/cajazeiras_brasil_3404020>. Acesso em 17 de novembro de 2018. 